\title{
Studi Pengaruh Kecepatan Potong dan Kedalaman Pemotongan Terhadap Kekasaran Permukaan Benda Hasil Pembubutan Menggunakan Pahat HSS Terhadap Material ST41
}

\author{
Rendi Wawanto*, Erwansyah, Ariyanto \\ Teknik Mesin \& Manufaktur,Teknik Mesin, Politeknik Manufaktur Negeri Bangka Belitung \\ *rendy.wawanto@gmail,com
}

\begin{abstract}
In the machining process is very need high precision to get a good result. One of the benchmarks of the quality of the surface of the product workmanship in the machining process is surface roughness.

The research was aimed at determining the contribution of the parameters of the machining process conducted on lathes. The research was conducted using lathes with machining process parameters that vary from cutting speed, and depth of nutrition, as well as using fixed parameters of feeding. The experiment was conducted using experimental method with the amount of cutting speed value (Vc) used by St 41 material of $20-25 \mathrm{~m} / \mathrm{min}$. The values used in this study were limited to 20,21 , and $22 \mathrm{~m} / \mathrm{min}(\mathrm{Vc})$ values and cutting depths of $0.5,0.8$, and $1.0 \mathrm{~mm}$.

Research shows the results of turning (Vc) $20 \mathrm{~m} / \mathrm{min}$. best depth using a cutting depth of $0.5 \mathrm{~mm}$ with a surface roughness value (Ra) of $2,743 \mu \mathrm{m}$, and $(\mathrm{Vc})$ of 21 $\mathrm{m} / \mathrm{min}$, the best depth using a depth of $0.5 \mathrm{~mm}$ with a surface roughness value (Ra) 1,495 $\mu \mathrm{m}$, and using (Vc) $22 \mathrm{~m} / \mathrm{min}$, the best depth uses a depth of $0.8 \mathrm{~mm}$ with a surface roughness value ( $\mathrm{Ra}) 1,376 \mu \mathrm{m}$. the best value of the turning process uses 3 cutting speeds and 3 cutting depths at the turning process using (Vc) $22 \mathrm{~m} / \mathrm{min}$ with a depth of $0.8 \mathrm{~mm}$ with a surface roughness value (Ra) 1,376 $\mu \mathrm{m}$
\end{abstract}

Keywords : lathe, roughness, experimentation, St41, velocity of cutting

\section{PENDAHULUAN}

Dimasa sekarang ini proses pemesinan pada industri manufaktur sangatlah dibutuhkan. Mesin sebagai peran utama pembantu manusia dalam proses produksi. Hal ini tidak dapat dipungkiri lagi karena dengan mesin pekerjaan manusia dapat menjadi lebih cepat, ringan, dan lebih baik hasilnya. Pekerjaan yang dilakukan pada proses pemesinan yang biasanya digunakan pada saat ini dapat berupa pembubutan, pengefraisan. Pengeboran, dan banyak lagi yang lainya (Pratama, 2016).

Proses pemesinan yang digunakan dalam proses produksi membutukan ketelitian yang tinggi untuk mendapatkan hasil yang baik. Ketelitian, kepresisian dan kualitas permukaan menjadi peroritas utama yang menjadi acuan dalam pengerjaan dalam proses pemesinan, hasil permukaan benda kerja yang baik salah satu yang diharapkan dari setiap pengerjaan. Tingkat kepresisian dan kekasaran permukaan benda kerja yang di hasilkan harus sesuai dengan kebutuhan. Semakin tinggi tingkat kualitas permukaan benda kerja semakin tinggi pula tingkat kepresisiannya. Pada tingkat kekasaran permukaan salah satunya merupakan faktor utama untuk evaluasi produk dapat diterima atau tidak bagi instansi / perusahaan maupun konsumen, kekasaran permukaan yang tinggi akan mengakibatkan kinerja komponen pasangan produk yang di hasilkan akan 
terganggu. Misalnya pada saat pemanfaatannya dapat menimbulkan keausan pada komponen pasangannya jika permukaan benda kerja tidak sesuai. Karena akan terjadi gesekan yang antara permukaan benda kerja jika memiliki kekasaran permukaan tinggi dapat mempercepat proses keausan diantara kedua benda pasangan. (Poppy., 2016 )

Proses permesinan apabila tidak memperhatikan faktor-faktor yang mempengaruhi proses penyayatan akan berdampak pada penurunan kualitas produk. hal ini perlu dipertimbangkan karena akan berdampak pada kerugian material dan cost production.

Proses bubut adalah proses pemesinan untuk menghasilkan bagianbagian mesin berbentuk silindris yang dikerjakan dengan menggunakan Mesin Bubut. Prinsip dasarnya dapat didefinisikan sebagai proses pemesinan permukaan luar benda silindris atau bubut rata, prisip kerja mesin bubut dengan benda kerja yang berputar dengan satu pahat bermata potong tunggal (with a single-point cuttingtool), dengan gerakan pahat sejajar terhadap sumbu benda kerja pada jarak tertentu sehingga akan membuang permukaan luar benda kerja. (Widarto, 2008)

Pada saat pembubutan dengan mesin bubut sering di lakukan penyayatan yang tebal dan kecepatan tinggi (Haight speed), agar memperoleh kualitas yang baik dari hasil pembubutan dan proses yang cepat, maka perlu diperhatikan adalah pemilihan material Cutting tool dan sudut pahat yang di gunakan. Apabila salah dalam memilih material Cutting tool dan sudut pahat maka akan berdampak pahat akan cepat mengalami keausan dan hasil produk memiliki kualitas tidak optimal.

Faktor-faktor yang menpengaruhi kualitas permukaan suatu benda kerja pada proses pemesinan diantaranya adalah pisau potong dalam proses pembuatannya, kecepatan penyayatan, posisi senter yang tidak tepat, getaran mesin, perlakuan panas yang kurang baik. (Pratama, 2016)

Dari fakto-faktor yang disebut diatas, masih banyak faktor lain yang mempengaruhi tingkat kekasaran, penelitian kekasaran permukaan benda kerja juga sudah sering dilakukan, penelitian ini bertujuan untuk meneliti dengan variasi yang baru seperti jenis benda kerja, jenis mesin, parameter-parameter kedalam pemotongan, kecepatan potong untuk mendapatkan kombinasi terbaik untuk nilai kekasaran permukaan.

Penelitian yang dilakukan (Andrias Maylana Pratama, 2016) menjelaskan bahwa dari hasil penelitian yang telah di lakukan behwasannya kecepatan potong berpengaruh terhadap variasi kecepatan potong. Semangkin tinggi kecepatan potong yang digunakan maka hasil kualitas semakin baik. Kecepatan potong yang tinggi mengakibatkan luas penampang bidang geser. Pada saat putaran spindel tinggi maka kecepatan potong akan sejalan dan mengakibatkan luas penampang semangkin sempit, penyempitan luas penampang yang di hasilkan akan berpengaruh semakin baik pada hasil kualitas permukaan. Terbukti bahwa pada putaran 720 Rpm menghasilkan kualitas kekasaran terbaik yaitu $1,541 \mu \mathrm{m}, 2,166 \mu \mathrm{m}$, dan $2,258 \mu \mathrm{m}$.

Dari hasil penelitian yang dilakukan (Raul, widiyanti, Poppy, 2016) diperoleh bahwasanya kecepatan potong berpengaruh terhadap hasil kualitas permukaan benda kerja. Ada perbedaan tingkat kekasaran permukaan hasil pembubutan pada variasi kecepatan potong. Semakin tinggi kecepatan potong yang digunakan maka hasil kualitas semakin baik. Dalam gabungan antara kecepatan potong dan kedalaman potong ditemukan bahwa hasil kekasaran yang paling baik (paling halus) adalah kecepatan putar $2000 \mathrm{rpm}$ pada kecepatan potong $170 \mathrm{~m} /$ menit dan perbandingan kedalaman potong 0,6. Dari hasil pengukuran didapatkan dengan menggunakan kecepatan potong yang rendah dan kedalaman potong yang besar menghasilkan kualitas permukaan yang kurang baik karena mengakibatkan gaya pemotongan dan beban pemotongan yang 
menjadi tinggi.

\section{METODE PENELITIAN}

Hasil pengumpulan data observasi dari berbagai sumber, kemudian dilakukan eksperimen yaitu dengan melakukan proses pembubutan benda kerja menggunkan mesin bubut konvensional dan kemudian hasil pembubutan benda kerja dilakukan proses pengujian kekasaran permukaan menggunakan alat uji surface roughness tester. Dalam penelitian ini dapat di jelaskan dengan digaram alir peneletian sebagai berikut:

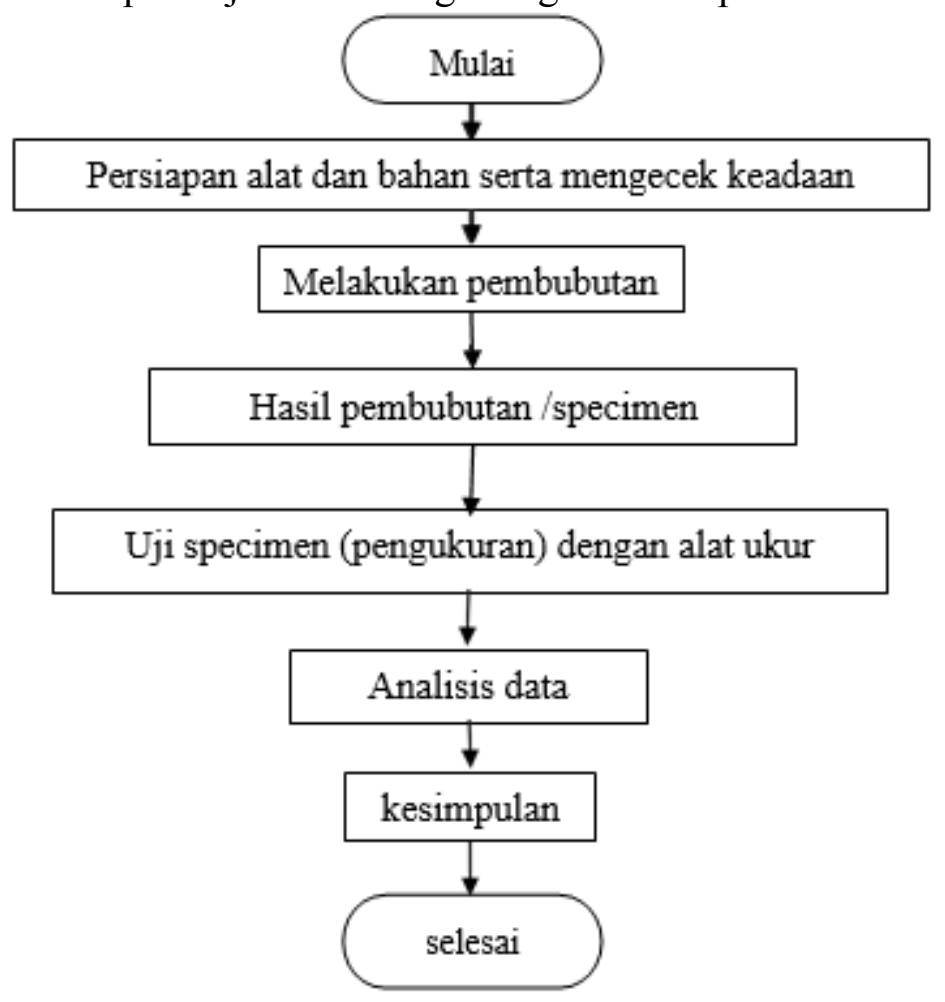

Gambar 1. Diagram alir penelitian

Penelitian ini bertujuan untuk mengetahui nilai kekasaran permukaan dengan mengvariasikan kecepatan potong (vc) 20, 21, 22 dan kedalaman pemotongan 0,5, 0,8, $1,0 \mathrm{~mm}$ dan mengunakan kecepatan pemotongan (feeding) yang sama yaitu 0,040 $\mathrm{mm} /$ put dengan benda kerja berbahan baku St 41

\subsection{Prosedur Penelitian}

Prosedur penelitian pada masing-masing spesimen akan dilakukan pembubutan poros memanjang dan pengasahan pahat dengan bentuk dan ukuran yang sama. Berikut adalah langkah-langkah penelitian sebagai brikut:

a) Pahat bubut yang di gunakan adalah pahat HSS $1 / 2 \times 6$ Bohler

b) Seting putaran $255 \mathrm{rpm}, 268 \mathrm{rpm}, 280 \mathrm{rpm}$. Kedalaman pemotongan 0,5, 0,8, 1,0 dan kecepatan pemakanan 0,040

c) benda kerja St 41 bentuk poros dengan ukuran diameter $25 \mathrm{~mm}$ panjang $100 \mathrm{~mm}$, dengan jumlah 9 pcs. 


\subsection{Pengumpulan Data}

Pengumpulan data sesuai dengan metode yaitu metode eksperimen, yaitu dengan melakukan pengujian dengan surface roughnees pada objek pembubutan yang telah dilakukan pada masing-masing pengujian untuk mendapatkan nilai kekasaran yang ingin diketahui dan dikelola untuk mendapatkan rata-rata dan dibuat diagram agar mempermudah untuk mengetahui perbedaan hasil dari eksperimen, pembuutan dilakukan dengan 9 pcs masing-masing benda kerja akan di lakukan satu kedalaman pemotongan,

Pada proses pembubutan benda kerja atau bahan akan menghasilkan kekasaran yang berbeda-beda dan ini yang akan menjadi objek penelitian yang akan di ukur tingkat kekasarannya. Gambar 2 berikut adalah foto bahan yang telah dilakukan pembubutan.

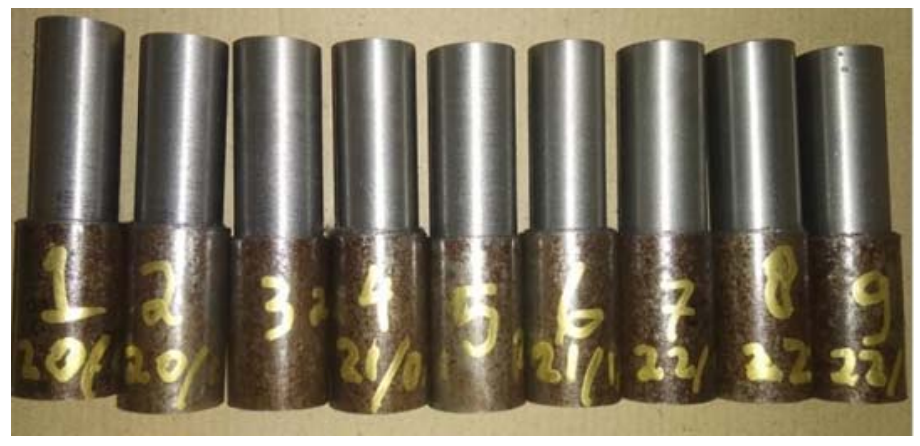

Gambar 2. Bahan yamg telah di lakukan pembubutan

Lalu di lakukan pengujian pada objek yang telah dilakukan pembubutan, berikut adalah langkah-langkah pengujian yang di lakukan sesuai prosedur :

a) Benda kerja yang akan diuji yang selesai dibubut akan diletakan pada v-blok yang berada di atas meja rata,

b) Surface roughness dipasang pada dial stand,

c) Dial stand dimana terdapat ujung sensor dari surface roughness tester juga diletakan pada meja rata,

d) Ujung sensor dari surface rougness tester disentuhkan pada benda uji,

e) Surface roughness tester diaktifkan untuk untuk melakukan proses pengukuran kekasaran permukaan sepanjang $5 \mathrm{~mm}$ dan dilakukan 3 kali pengukuran pada sumbu yang sama,

f) Hasil kekasaran permukaan dapat dilihat pada layar display surface roughness tester,

g) Benda uji dibebaskan dari ujung sensor surface roughness tester dan diputar sebesar $90^{\circ}$ untuk mendapatkan permukaan yang berbeda,

h) Langkah ke-empat hingga ke-enam diulang kembali untuk mendapatkan hasil kekasaran permukaan pada benda uji yang sama. Hal ini dilakukan berulang

i) hingga mendapatkan 9 data nilai kekasaran aritmatik $(\mathrm{Ra})$ pada tiap benda uji. Gambar 3 adalah skema proses pengukuran kekasaran permukaan material. 


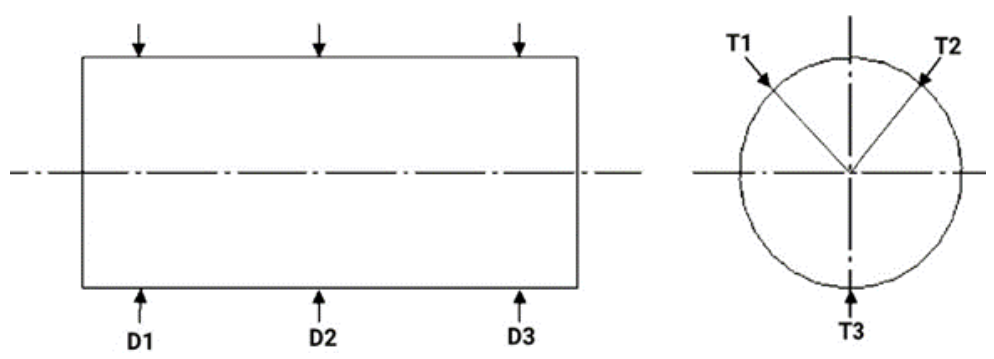

Gambar 3. Skema proses pengukuran kekasaran permukaan material

\section{HASIL DAN PEMBAHASAN}

Hasil pembubutan tentu akan menghasilkan nilai kekasaran yang berbeda, yang dapat dilihat pada tabel 1 .

Tabel 1. Hasil pengujian yang di lakukan.

\begin{tabular}{cccc}
\hline No & $\begin{array}{c}\text { Kecepatan potong } \\
(\mathrm{vc}) \mathrm{m} / \text { menit }\end{array}$ & $\begin{array}{c}\text { Kedalaman potong } \\
(\mathrm{mm})\end{array}$ & $\begin{array}{c}\text { Hasil Pengukuran } \\
\text { Kekasaran }(\mu \mathrm{m})\end{array}$ \\
\hline \multirow{3}{*}{1} & \multirow{2}{*}{20} & 0,5 & 2,743 \\
& & 0,8 & 3,621 \\
& \multirow{3}{*}{21} & 1 & 4,405 \\
2 & & 0,5 & 1,495 \\
& \multirow{2}{*}{22} & 0,8 & 3,817 \\
3 & & 1 & 4,171 \\
& & 0,5 & 1,376 \\
& & 0,8 & 3,235 \\
& & 1 & 3,590 \\
\hline
\end{tabular}

Pengujian kekasaran dilakukan untuk mengetahui tingkat kekasaran dari beberapa proses yang dilakukan pembubutan pada benda kerja St 41, dalam pembubutan ini di lakukan pembubutan dengan (vc) 20 dengan benda kerja 1 dengan kedalaman 0,5mm, benda kerja 2 dengan kedalaman $0,8 \mathrm{~mm}$, dan benda keja 3 dengan kedalaman $0,1 \mathrm{~mm}$, (vc) 21 dengan benda kerja 1 dengan kedalaman $0,5 \mathrm{~mm}$, benda kerja 2 dengan kedalaman 0,8 mm, dan benda keja 3 dengan kedalaman 0,1 mm, (vc) 22 dengan benda kerja 1 dengan kedalaman $0,5 \mathrm{~mm}$, benda kerja 2 dengan kedalaman $0,8 \mathrm{~mm}$, dan benda kerja 3 dengan kedalaman $0,1 \mathrm{~mm}$,

Dapat dilihat dari tabel di atas bahwa dari kecepatan potong (vc) 20 pada kedalaman 0,5 mm memiliki hasil tingkat kekasaran terendah (Ra) 2,743 dan pada kecepatan potong (vc) 21 pada kedalaman $0,5 \mathrm{~mm}$ memiliki hasil tingkat kekasaran terendah ( $\mathrm{Ra}$ ) 1,495 dan pada kecepatan potong (vc) 22 pada kedalaman 0,5 mm memiliki hasil tingkat kekasaran terendah (Ra) 1,376. Hasil nilai kekasaran dapat di tuangkan kedalam gambar grafik agar mempermudah dan meperjelas perbedaan tingkat kekasaran dari 9 benda kerja yang telah di lakukan pembubutan. 


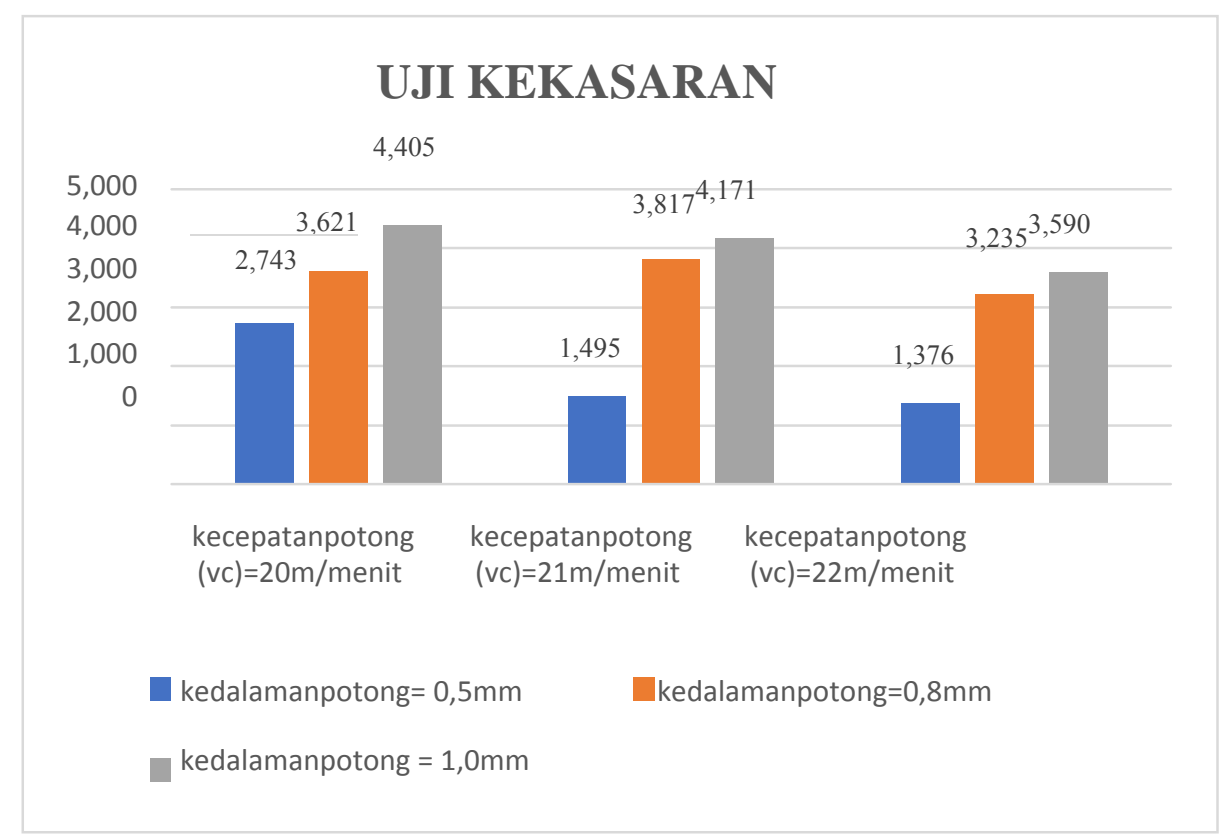

Gambar 4. Grafik uji kekasaran 9 benda kerja.

Lalu dilakukan analisa kembali dari 9 kali proses pembubutan dengan menggunakan pahat HSS $1 / 2 \times 6$ Bohler dengan 3 kedalaman pemotongan 0,5, 0,8, 1,0 mm dan vc 20, 21, 22 $\mathrm{m} /$ menit bahwa nilai kekasaran terbaik pada kedalaman pemotongan 0,5 pada kecepatan potong(vc) $22 \mathrm{~m} /$ menit sedangkan dengan kedalaman pemotongan $0,8 \mathrm{~mm}$ pada kecepatan potong (vc) $22 \mathrm{~m} /$ menit dan pada kedalaman pemotongan 1,0 mm pada kecepatan potong (vc) $22 \mathrm{~m} /$ menit.

\section{KESIMPULAN}

Berdasarkan dari proses pembubutan yang dilakukan dengan tiga kecepatan potong (Vc) 20, 21, dan 22 dengan tiga kedalaman pemotongan 0,5, 0,8, dan 1,0 bahwa hasil pembubutan dengan kecepatan potong $(V C) 22$ dan kedalaman potong $0,5 \mathrm{~mm}$ dengan pengujian menggunakan surface roghness terter memperoleh nilai 1,376 hasil ini adalah nilai terbaik atau terhalus dari 9 proses pembubutan lainnya.

\section{DAFTAR PUSTAKA}

1. Munadi, D.S. (1988). Dasar-dasar metrologi industri. Jakarta: Proyek Pengembangan Lembaga Pendidikan Tenaga Kependidikan.

2. Rochim,T.(2001). Spesifikasi, Metrologi, \& Kontrol Kualitas Geometrik. Bandung: Penerbit ITB.

3. Widarto.(2008). Teknik Permesinan. Jakarta: Depdiknas.

4. Adrianto, R. (2010 ). Pengaruh Kecepatan Spindel, Kecepatan Pemakanan Dan Kedalaman Pemakanan Terhadap Tingkat Kekasaran Permukaan Benda Kerja Hasil Permesinan Bubut Cnc Pada Baja ST41. Perpustakaan.uns.ac.id .

5. Husein,S.(2015). Pengaruh Sudut Potong Terhadap Getaran Pahat Dan Kekasaran Permukaan Pada Proses Bubut Mild Steel ST 41. Program Study Strata Satu Teknik FAKULTAS TEKNIK UNIVERSITAS JEMBER, 28.

6. Pratama, A.M.(2016). Pengaruh Kadar Campuran Pendingin Dan Variasi Kecepatan Penyayatan Baja ST 37 Pada Mesin Bubut Konvesional Terhadap 
Kekasaran Benda Kerja. simki.unpkediri.ac.id, 5.

7. Poppy., R. w. (2016 ). Pengaruh Variasi Kecepatan Potong Dan Kedalaman Potong Pada Mesin Bubut Terhadap Tingkat Kekasaran Permukaan Benda Kerja ST 41, Jurnal Teknik Mesin, 1-5.

8. Media Nofri, \& Taryana, A. (2017). Analisa Sifat Mekanik Baja SKD 61 Dengan Baja ST 41 Dilakukan Hardening Dengan Variasi Temperatur. BINA TEKNIKA,13-191. 